\title{
Large suprasellar craniopharyngioma surgery in adults through the trans-eyebrow supraorbital approach
}

\author{
Ricardo Prat-Acín $^{1,2,3}$ (1) - Inma Galeano ${ }^{1,2}$ • Rocío Evangelista ${ }^{1}$ • Giovanni Pancucci ${ }^{1}$ • \\ Juliana Guarín $^{1} \cdot$ Angel Ayuso-Sacido $^{4} \cdot$ Mukesh Misra $^{5}$
}

Received: 7 June 2017 / Accepted: 12 June 2017 / Published online: 24 June 2017

(C) Springer-Verlag GmbH Austria 2017

To the Editor,

We really appreciate the comments on our paper made by Prieto et al. in their letter to the editor "Optic chasm distortions in craniopharyngiomas: a sign of hypothalamic involvement". After carefully reading the letter, we would like to clarify two essential points. One is that though we are aware of the importance of hypothalamic involvement in achieving a complete resection of suprasellar craniopharyngiomas, our paper focuses on a particular approach: the trans-eyebrow supraorbital approach and all conclusions should only be applied for this approach [1-4]. In our experience, when performing the resection of a large craniopharyngioma through this approach, dealing with a short optic nerve negatively affects the extent of resection as an independent variable. The second aspect to be taken into consideration is that our article tries to offer a quantitative tool in the form of a linear regression model to calculate the extent of resection. This model seems to predict resection of large craniopharyngiomas more accurately than the optic chiasm location, which appears to be less precise in the normal optic chiasm location.

\section{References}

1. McLaughlin N, Ditzel Filho LF, Shahlaie K, Solari D, Kassam AB, Kelly DF (2011) The supraorbital approach for recurrent or residual suprasellar tumors. Minim Invasive Neurosurg 54:155-161

2. Raza SM, Garzon-Muvdi T, Boaehene K, Olivi A, Gallia G, Lim M, Subramanian P, Quinones-Hinojosa A (2010) The supraorbital craniotomy for access to the skull base and intraaxial lesions: a technique in evolution. Minim Invasive Neurosurg 53:1-8

3. Reisch R, Perneczky A (2005) Ten-year experience with the supraorbital subfrontal approach through an eyebrow skin incision. Neurosurgery 57:242-255

4. Tawk RG, Binning MJ, Thomas JM, Siddiqui AH, Grand W (2014) Transciliary supraorbital approach (eyebrow approach) for resection of retrochiasmatic craniopharyngiomas: an alternative approach, case series, and literature review. J Neurol Surg A Cent Eur Neurosurg 75: 354-364

Ricardo Prat-Acín

ricprat@hotmail.com

Hospital Universitario y Politécnico La Fe, Valencia, Spain

2 Hospitales NISA, Valencia, Spain

3 Department of Neurosurgery, Hospital La Fe Valencia, Paseo Alameda, 64 - $10^{\circ}$ - pta 47, 46023 Valencia, Spain

4 Fundación de Investigación HM Hospitales, HM Hospitales, Madrid, Spain

5 Palmdale Medical Center, Palmdale, CA, USA 